\title{
Ascorbin 酸オキシダーゼの化學的性質（第九報）
}

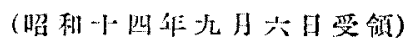

时所挴太䬦高杉直翰

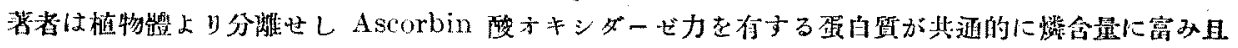

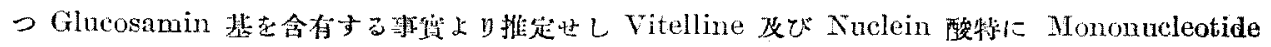

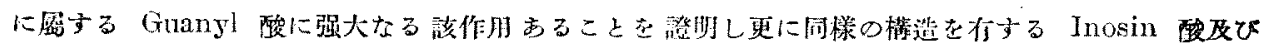
Co-Zymase に就さ检查せし絬果下の如し.

(1) Inosin 在含有する酸性液にありて Ascorbin 酸才キシダーゼの作胢を認むる能はず.

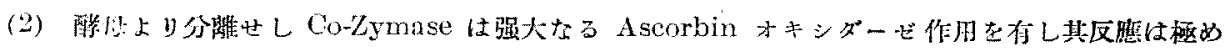

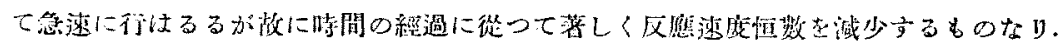

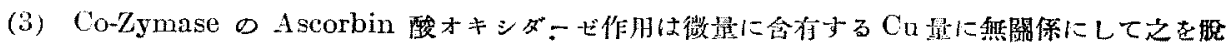

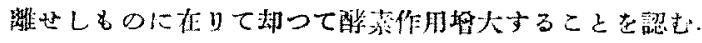

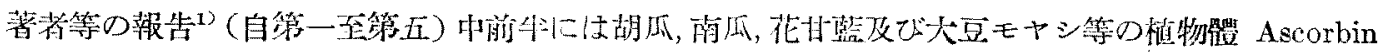

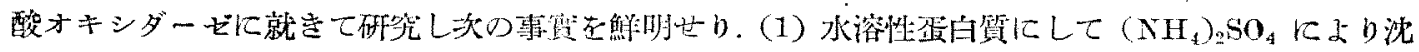

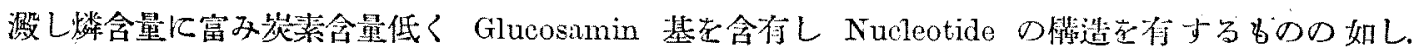

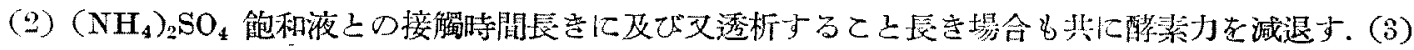

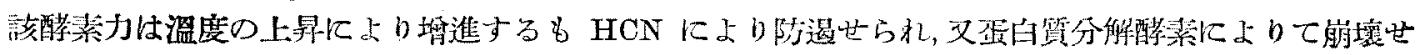

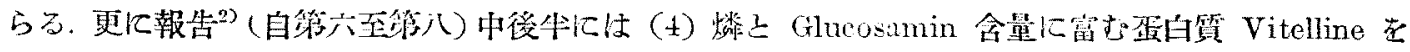

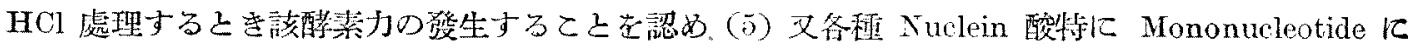

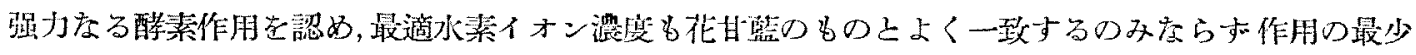

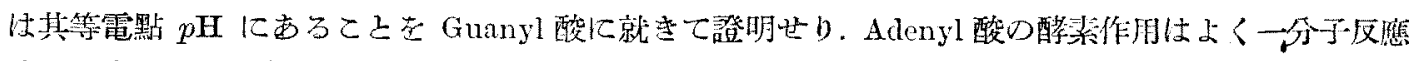

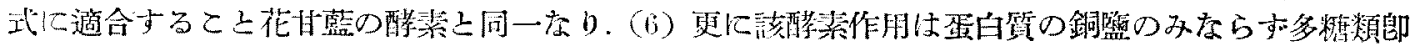

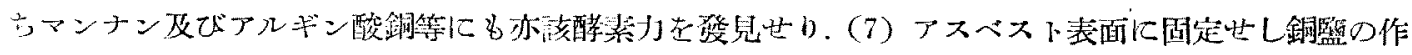

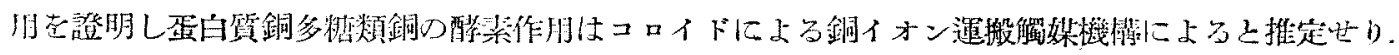

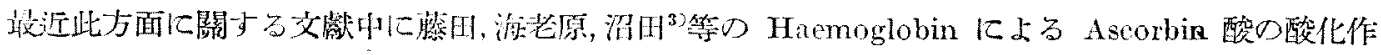

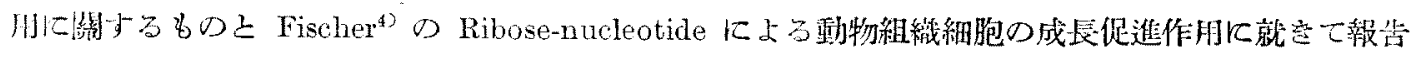

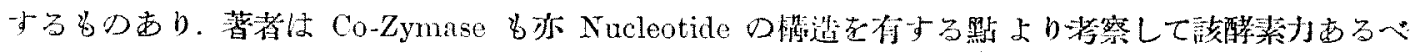

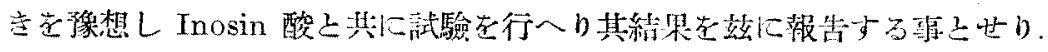

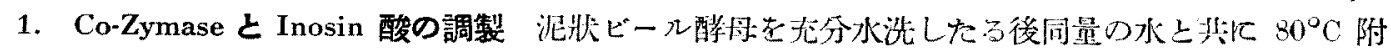

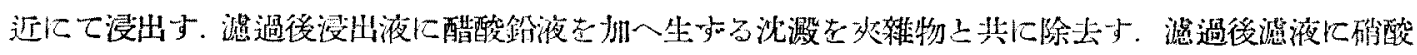

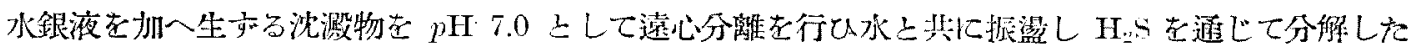

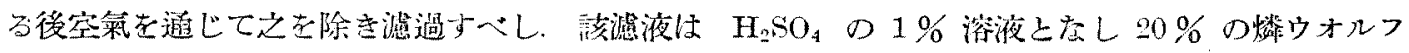

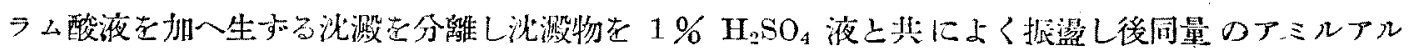

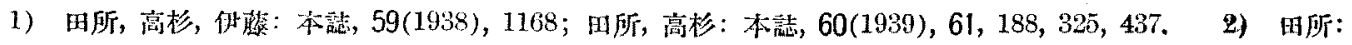

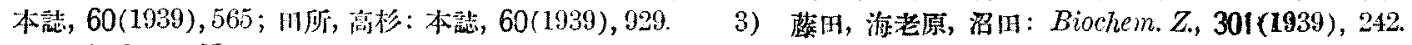
4) Fischer: Natuie, 144(1939), 113. 


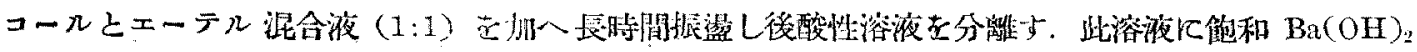

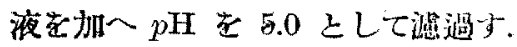

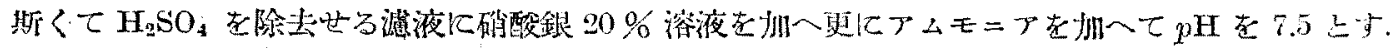

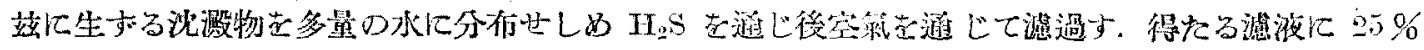

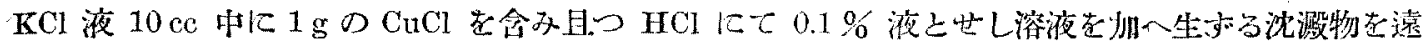

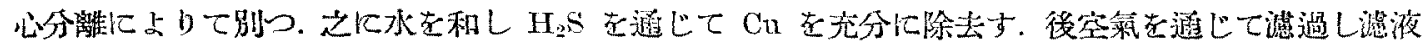

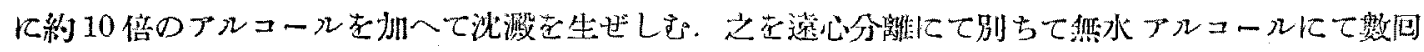

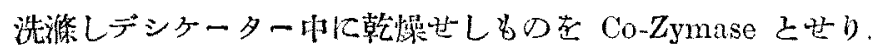

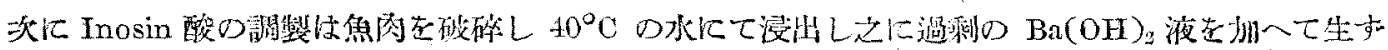

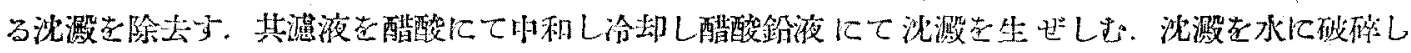

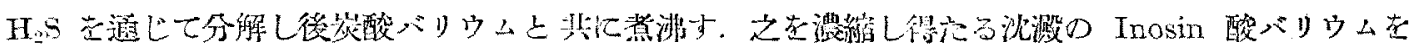

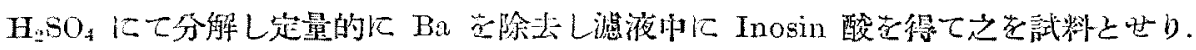

2. Co-Zymase 己 Inosin 酸の分析 前述のJ法により調犁したる Co-Zymase 及び Inosin 酸は

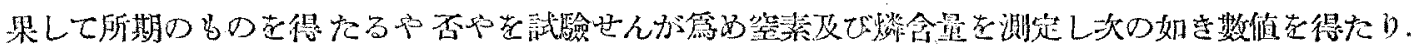

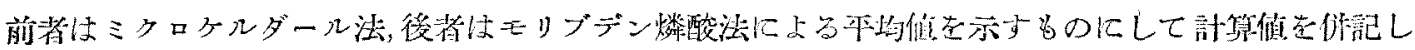
て比䡆咕り。

\begin{tabular}{|c|c|c|c|c|c|c|}
\hline Co-7ymose & 試 & $3.636 \mathrm{mg}$ & $\mathrm{N}=13.32 \%$ & 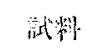 & $3.487 \mathrm{mg}$ & $N=13.00 \%$ \\
\hline & 郦 & $5.535 \mathrm{mg}$ & P-molybd. & & $25.89 \mathrm{mg}$; & $\mathbf{P}=6.79 \%$ \\
\hline & 塥粗 & $3.64 \mathrm{mg} ;$ & P-molybd. & & $17.25 \mathrm{mg}$ & $P=$ \\
\hline & 理諭数 & $\begin{array}{l}X=13.6- \\
V=1\end{array}$ & & $\begin{array}{l}=7.55 \\
=7.94\end{array}$ & $\begin{array}{l}-8.14 \% \\
\%\end{array}$ & \\
\hline
\end{tabular}

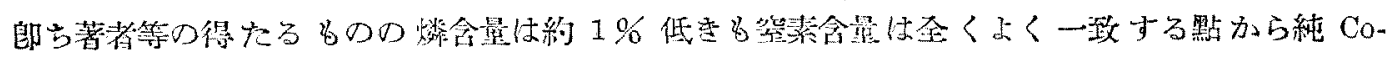
Zymase て近しと澕へらる.

Inosin 酸は溶液在りし考以て N/P 割合を理諭优に比較与る事上坆り即ち下の如し.

$$
\begin{aligned}
& \text { 理䕆値 } \mathrm{N}=16.10 \% \quad \mathrm{P}=8.90 \% \quad \mathrm{~N} / \mathrm{P}=1.808
\end{aligned}
$$

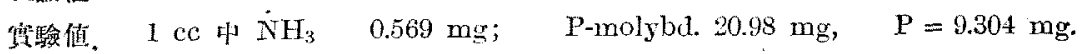

$$
\begin{aligned}
& \mathrm{N} / \mathrm{P}=1.870
\end{aligned}
$$

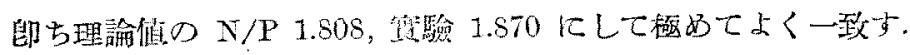

3. Co-Zymase と Inosin 酸の Ascorbin 酸オキシダーゼ作用の檢出 Co-Zymase の Ascorbin 酸

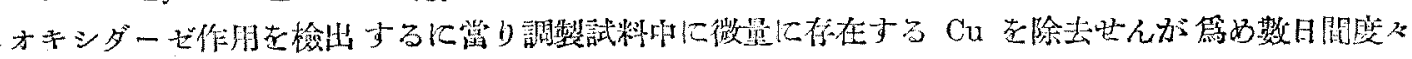

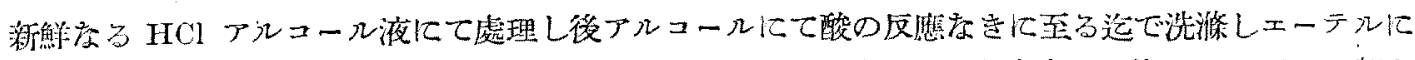

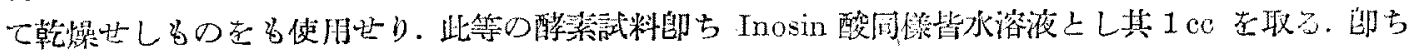
$\mathrm{H}_{2} \mathrm{O} \approx \mathrm{cc}, p \mathrm{H} 5.8$ の构枌酸バツフアー液 $2 \mathrm{cc}, \mathrm{Ascorbin}$ 酸の $0.025 \%$ 液 $1 \mathrm{cc}$ 女起混合し $35^{\circ} \mathrm{C}$ 恒

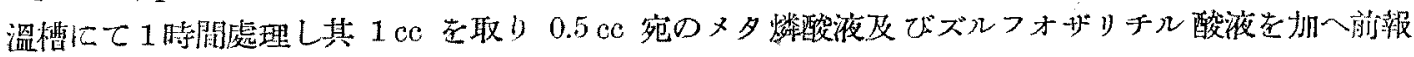

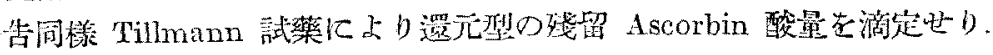

\begin{tabular}{|c|c|c|c|c|c|}
\hline \multirow[b]{2}{*}{ 斌粼 } & \multirow[b]{2}{*}{ 等試蹬 } & \multirow[b]{2}{*}{ Inosin 䧣 } & \multicolumn{3}{|c|}{ Co-Zymase } \\
\hline & & & 灌試料 & 㙫弪料 & Cu 䟕襍 \\
\hline 游定数(ce) & 2.28 & 2.25 & 0.53 & 0.50 & 0.29 \\
\hline
\end{tabular}

上表によ狄ば Inosin 酸には Ascorbin 酸オキシダーゼの作用茫發見する能はざるも Co-Zymase

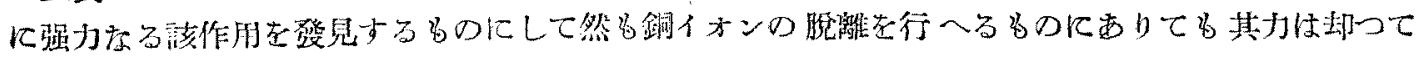




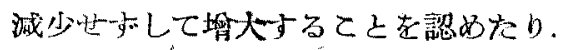

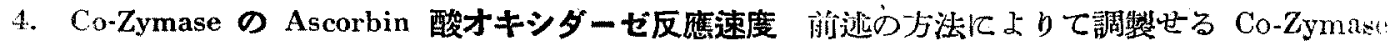

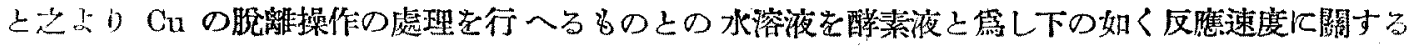

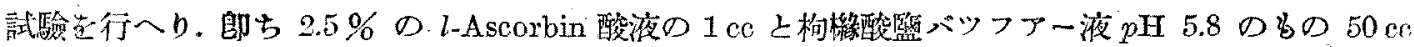

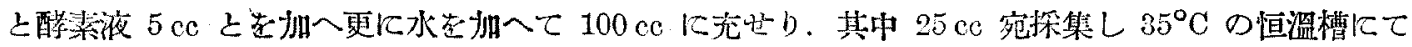

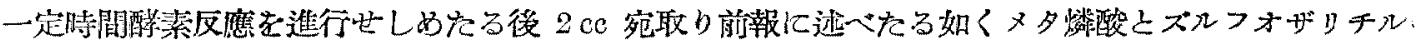

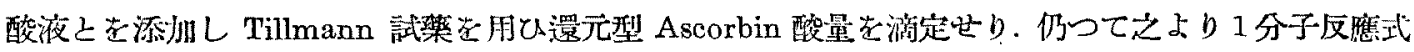
の恒数苦算㤕与ること下の如し.

\begin{tabular}{|c|c|c|c|c|c|c|}
\hline 双照時間 & 30 s & 45 分 & 60 分 & 75 分 & 10 分 & 120 分 \\
\hline 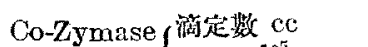 & 0.30 & 0.24 & 0.20 & 0.18 & 0.18 & 0.18 \\
\hline 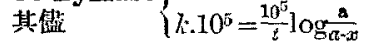 & $29 \pi$ & 220 & 178 & 154. & 128 & 96. \\
\hline 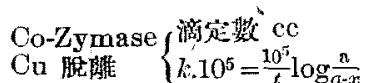 & 0.29 & 0.25 & 0.19 & 0.18 & 0.18 & 0.15 \\
\hline
\end{tabular}

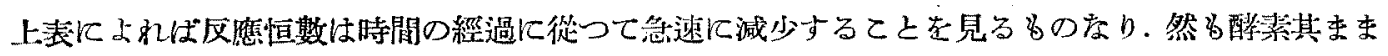

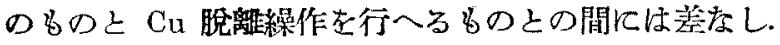

